\title{
IBL Modules Construction Experience and Developments for Future Upgrade
}

Kazuki Motohashi (Tokyo Institute of Technology, Japan)

on behalf of the ATLAS Collaboration

The first upgrade of the ATLAS Pixel Detector is the Insertable B-Layer (IBL), just installed in May 2014 in the core of the detector itself. Two different silicon sensor technologies, planar n-in-n and 3D, were used, connected with the new generation 130nm IBM CMOS FE-I4 readout chip via solder bump-bonds. Production quality control tests were set up to verify and rate the performance of the modules before integration onto staves. An overview of module design and construction, the quality control results and production yield will be discussed, as well as future developments foreseen for future detector upgrades.

\section{ATLAS Pixel Detector \& Insertable B-Layer (IBL)}

The ATLAS Pixel detector is the innermost part of the ATLAS detector. It provides charged particle tracking with high efficiency over a wide angle range. In the LHC Run2 (2015-), with high beam energy and high luminosity the event pileup is increased, leading to high occupancy that can induce readout inefficiencies. In order to preserve tracking performance, a fourth layer of the Pixel detector called Insertable B-Layer (IBL) has been inserted between a new beam pipe and the inner Pixel layer (B-layer). The IBL located close to the interaction point at $R \sim 3 \mathrm{~cm}$ significantly improves the performance of vertexing, b-quark tagging, etc. The IBL project provides a test of technologies for the future upgrade of the pixel detector at very high luminosity around $5 \times 10^{34} \mathrm{~cm}^{-2} \mathrm{~s}^{-1}$

\section{Flow of the IBL Module Construction}

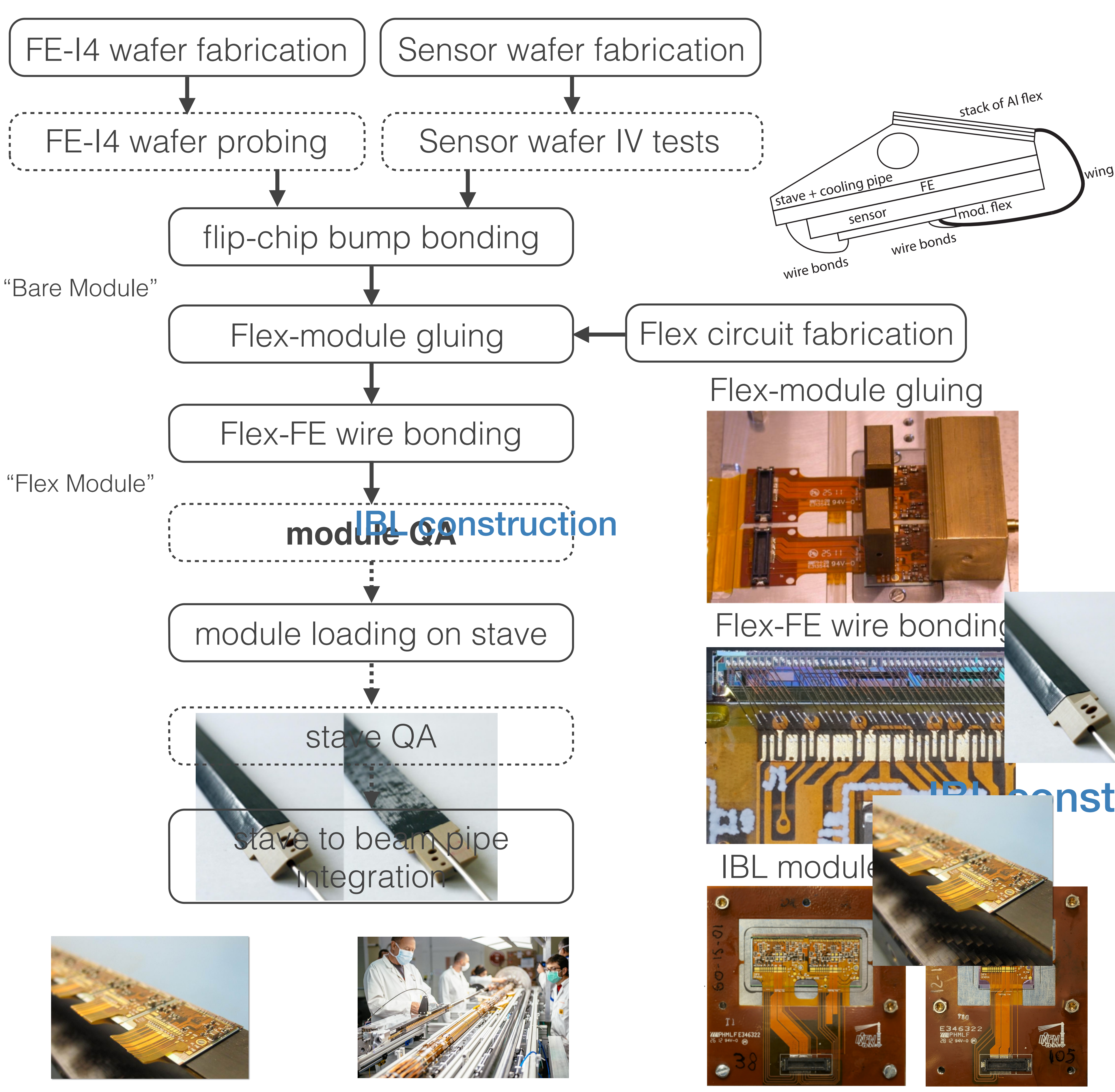

Trend of the Module Production

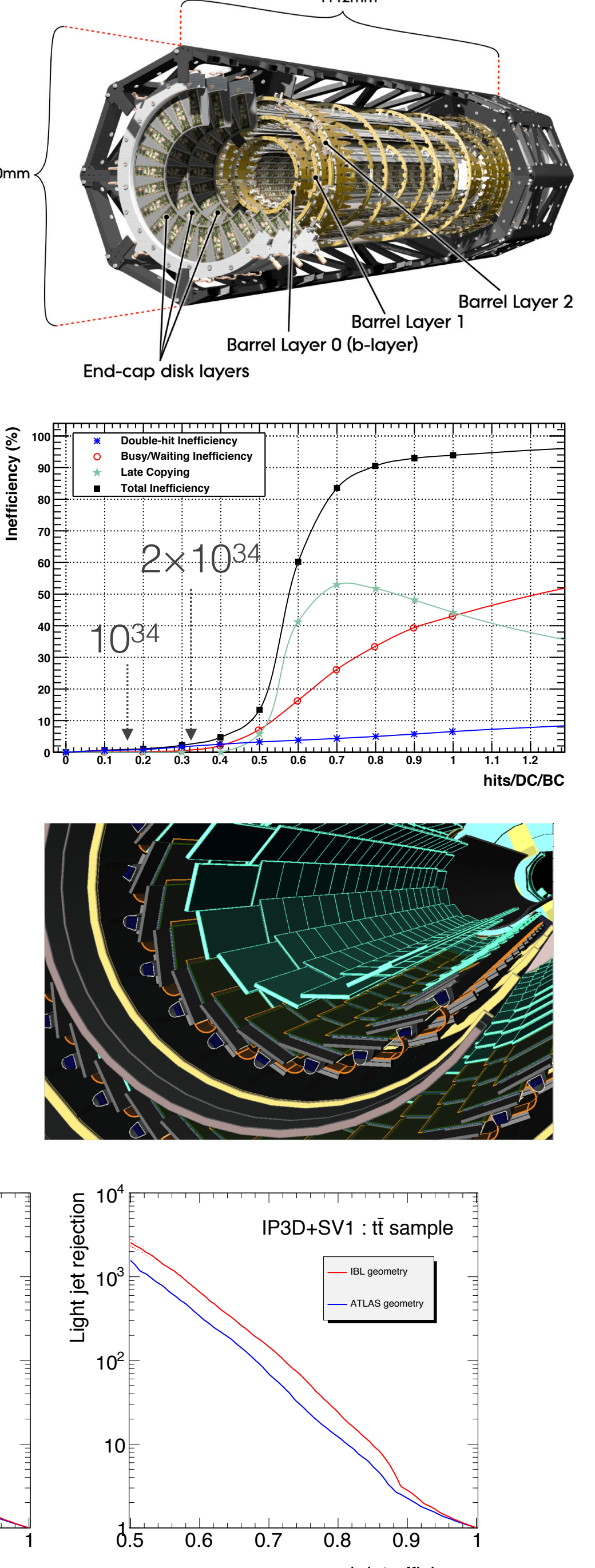

\section{Planar (>168 required)}

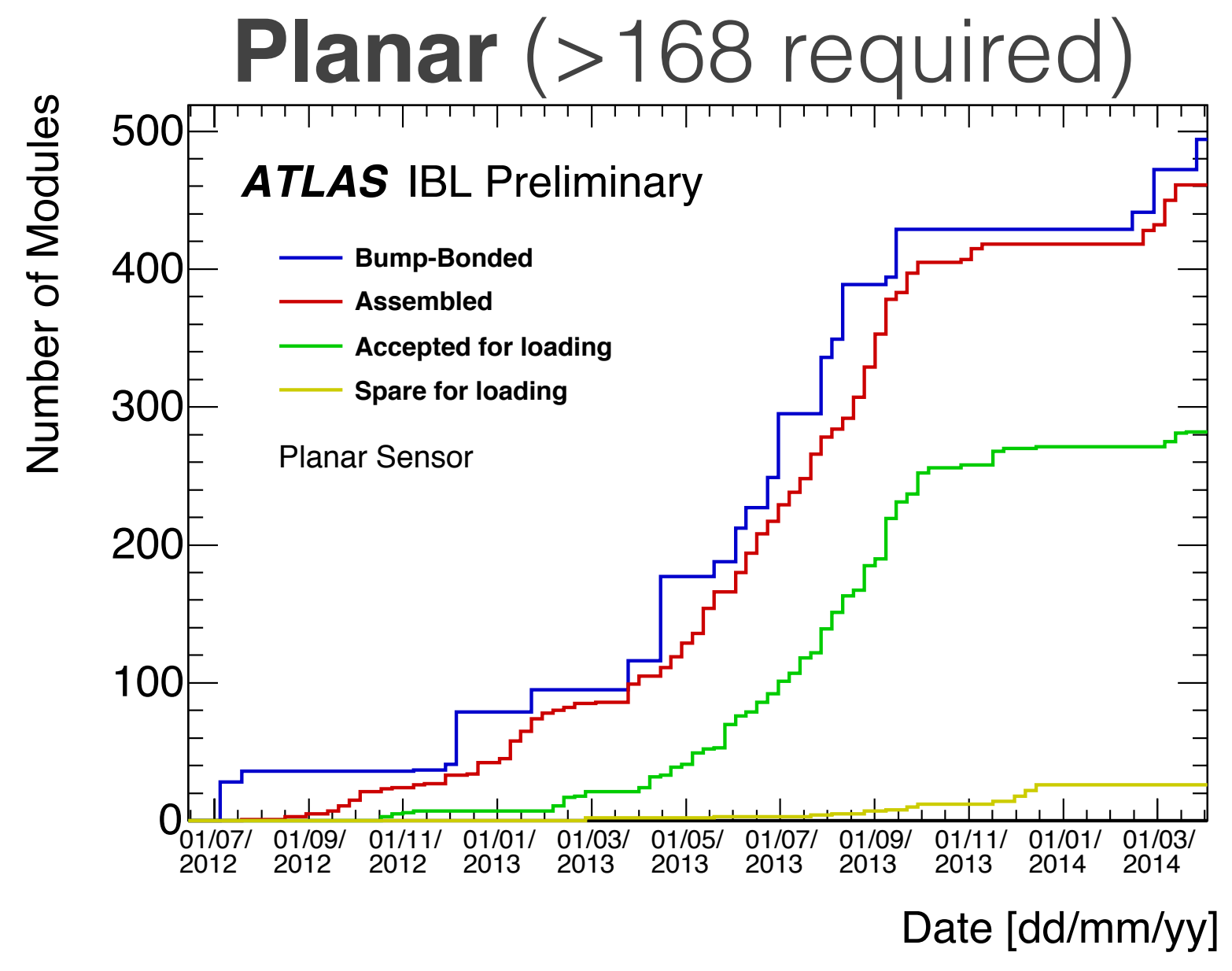

3D (>112 required)

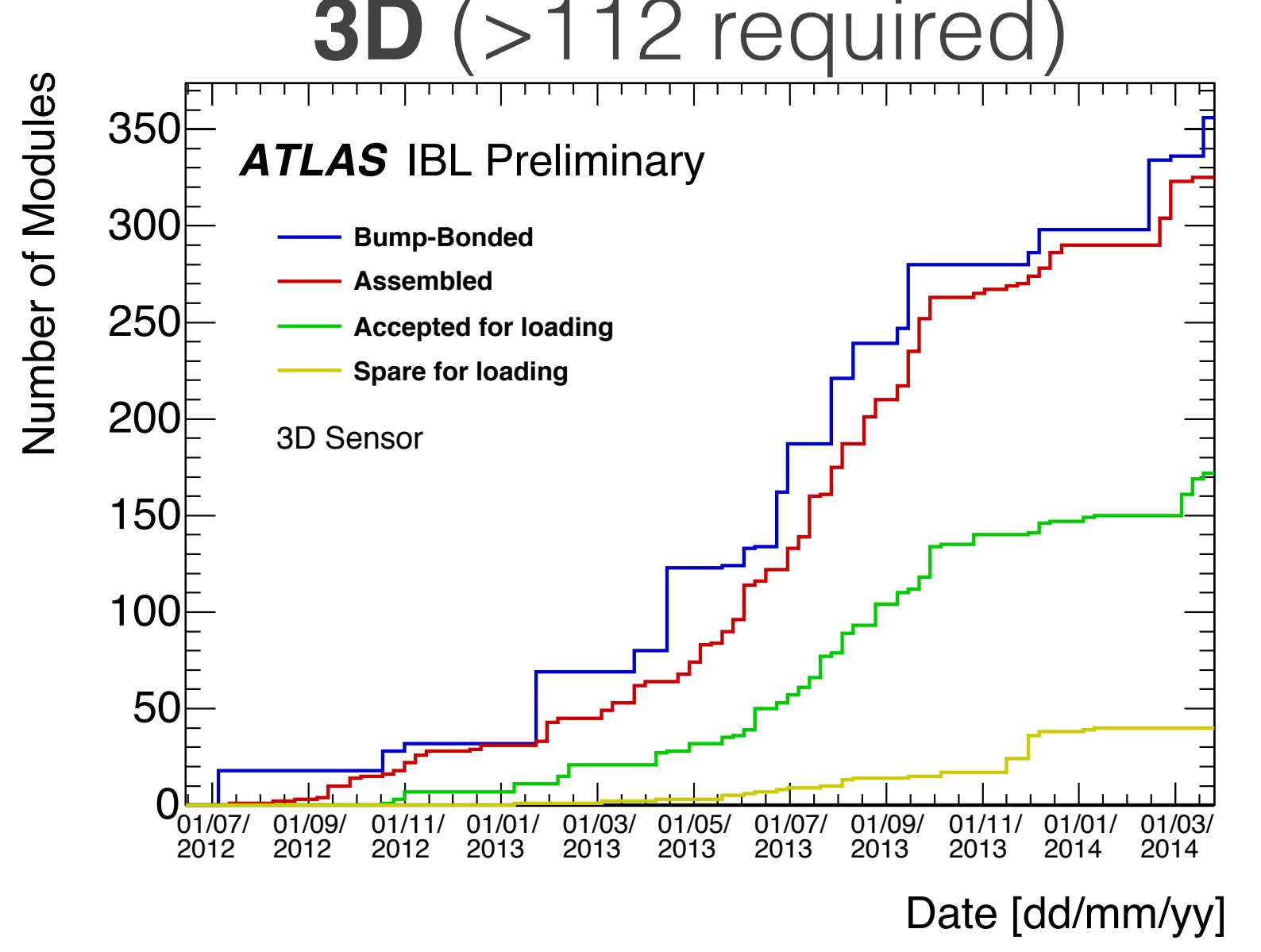

\section{IBL Sensors \& Front-End Chip}

The IBL staves are populated in the centre with double-chip planar sensor modules and in the forward with single-chip 3D sensors.

1. Planar sensor by CiS

Conservative established technology type: n-in-n

thickness: $(250 \mu \mathrm{m} \rightarrow) 200 \mu \mathrm{m}$ inactive edge: $(1100 \mu \mathrm{m} \rightarrow) 200 \mu \mathrm{m}$

2. $3 \mathrm{D}$ sensor by CNM \& FBK

New technology with complex fabrication process

type: n-in-p

thickness: $230 \mu \mathrm{m}$ inactive edge: $200 \mu \mathrm{m}$
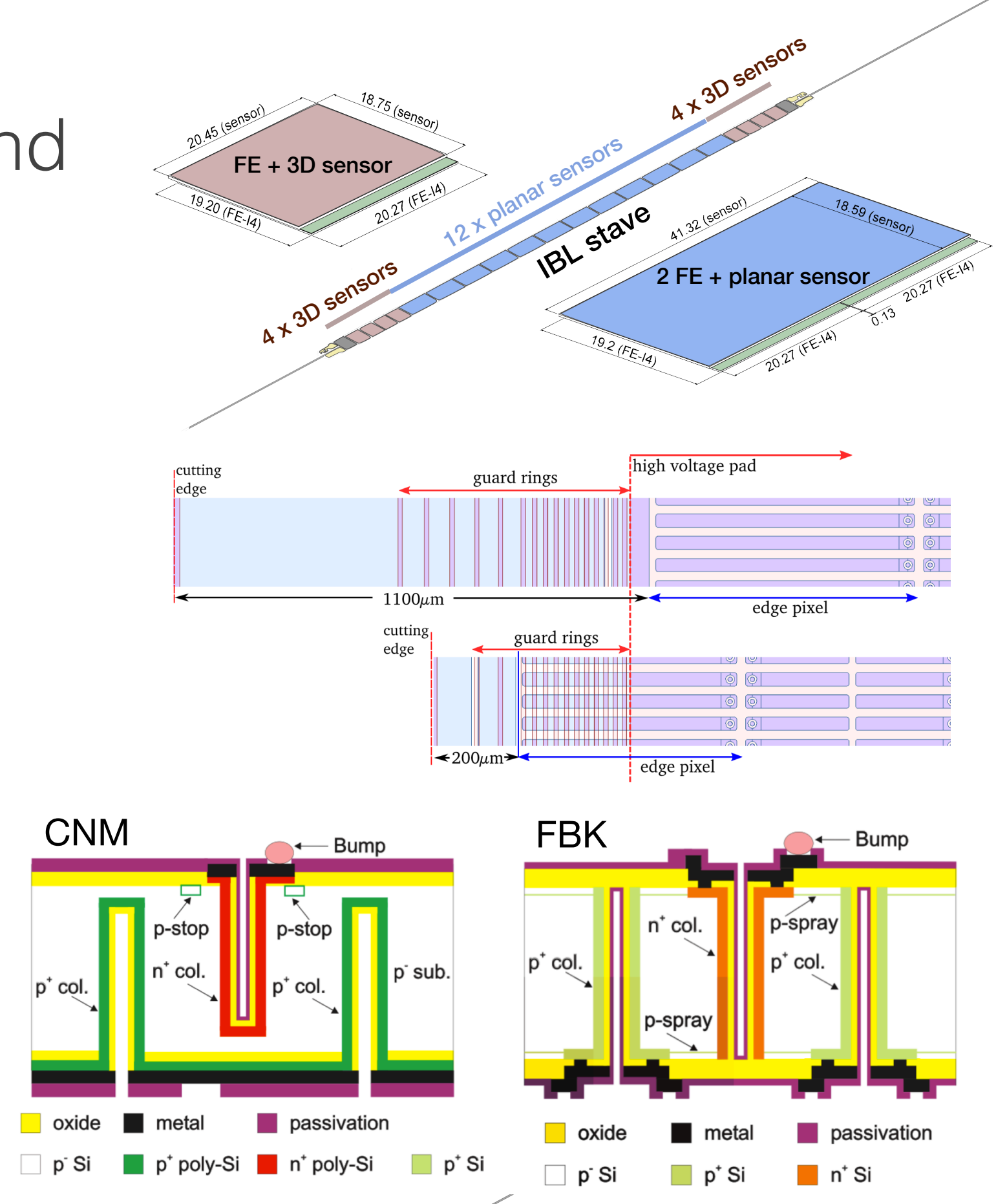

A new front-end chip, FE-I4, is connected with

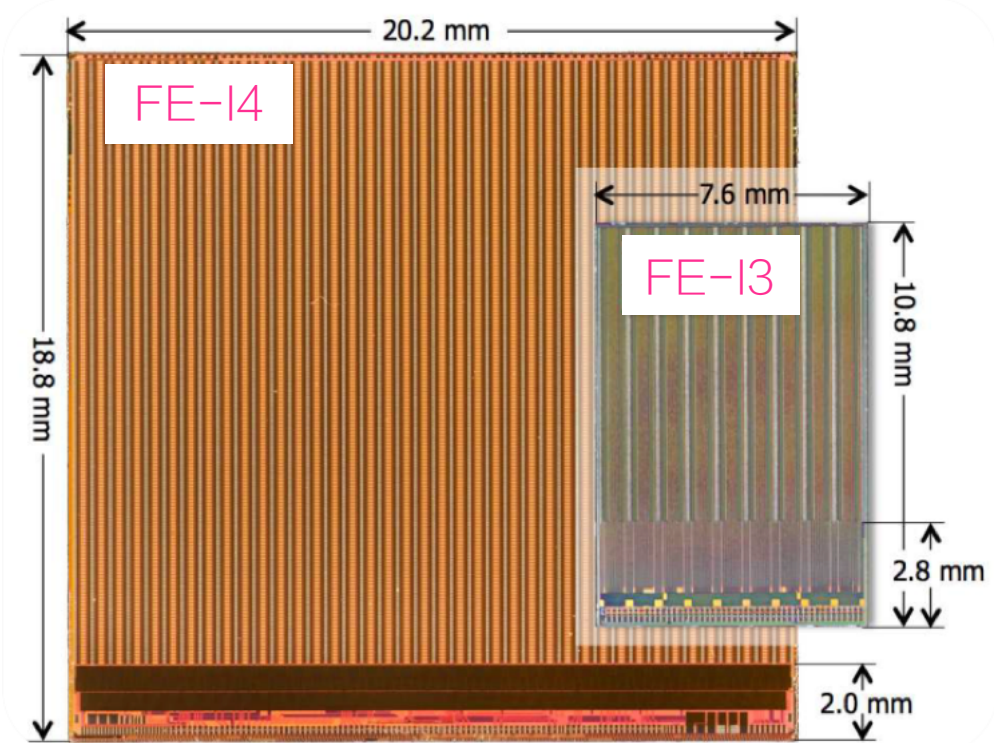

a sensor by flip-chip bump bonding.

Largest FE chip of pixel detector for HEP

$130 \mathrm{~nm}$ CMOS technology

26,880 pixels $\left(50 \times 250 \mu m^{2}\right)$

Active area up to $90 \%$

Local memory-based architecture

\section{IBL Module QA}

In order to select modules with good performance, a number of modules ( 900) were tested and ranked. The QA procedure is divided into several processes. Obviously bad modules are thinned out in the early stage and not tested thereafter for saving time.

1. Preliminary electrical test after assembly check if wire-bonds properly done

2. Electrical test at ambient temperature IV curve, noise scan, etc

3. Thermal cycling between $-40^{\circ} \mathrm{C}$ and $+40^{\circ} \mathrm{C}$

4. Complete test and calibration at operation temperature $\left(\sim-15^{\circ} \mathrm{C}\right)$ electrical test, $\boldsymbol{\beta}$-source scan

ß-source scan

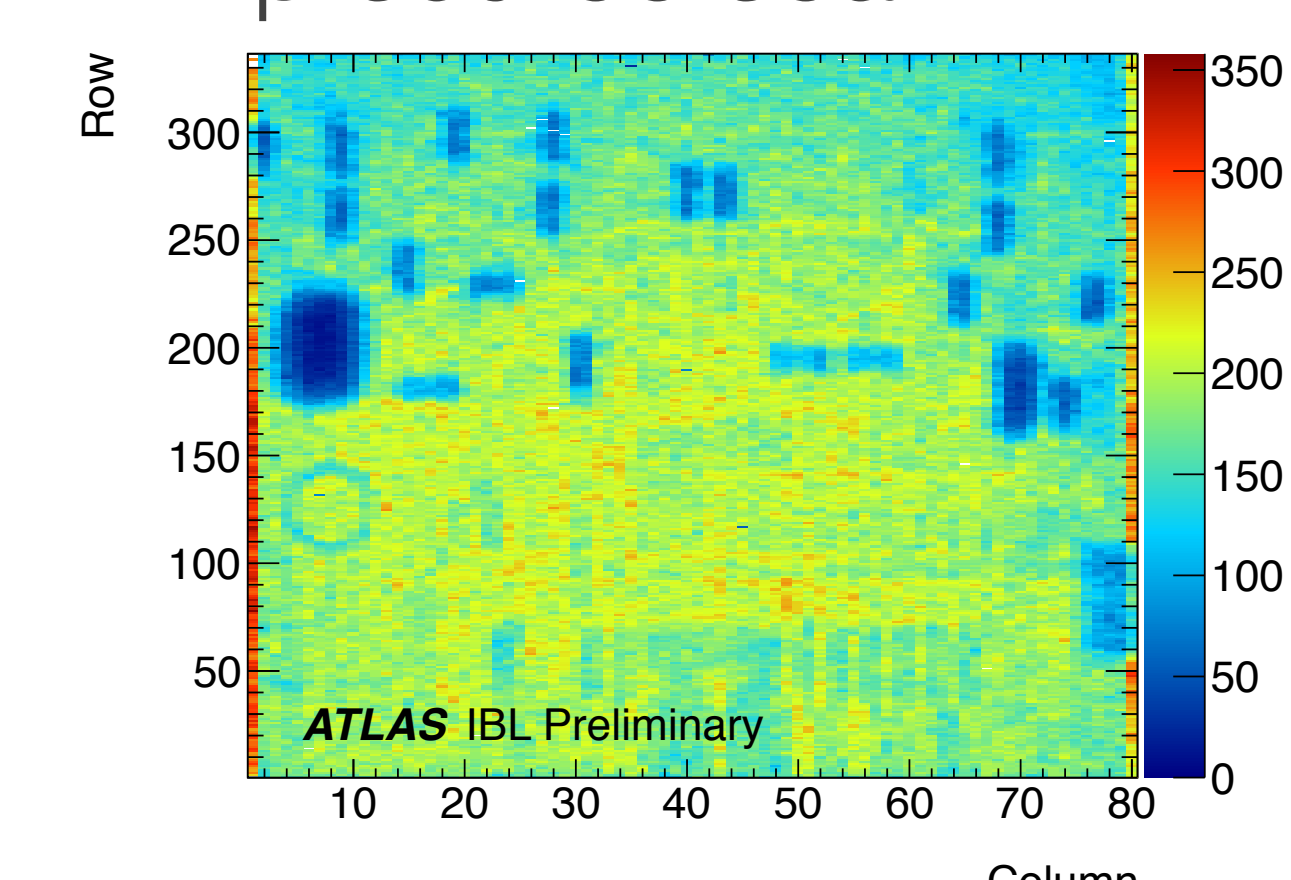

IBL requirement:

$<1 \%$ pixel defects per FE Breakdown voltage

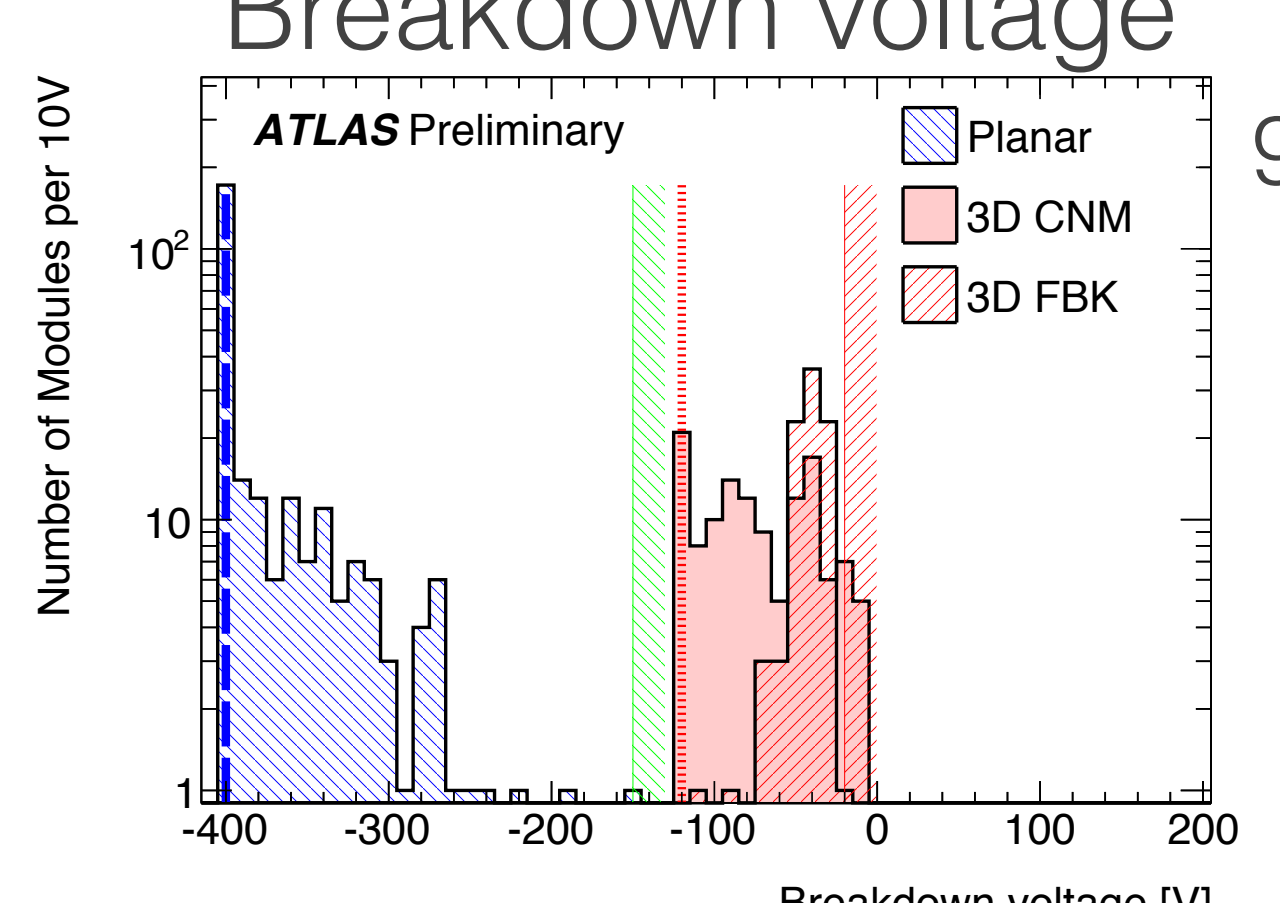

Equivalent Noise Charge

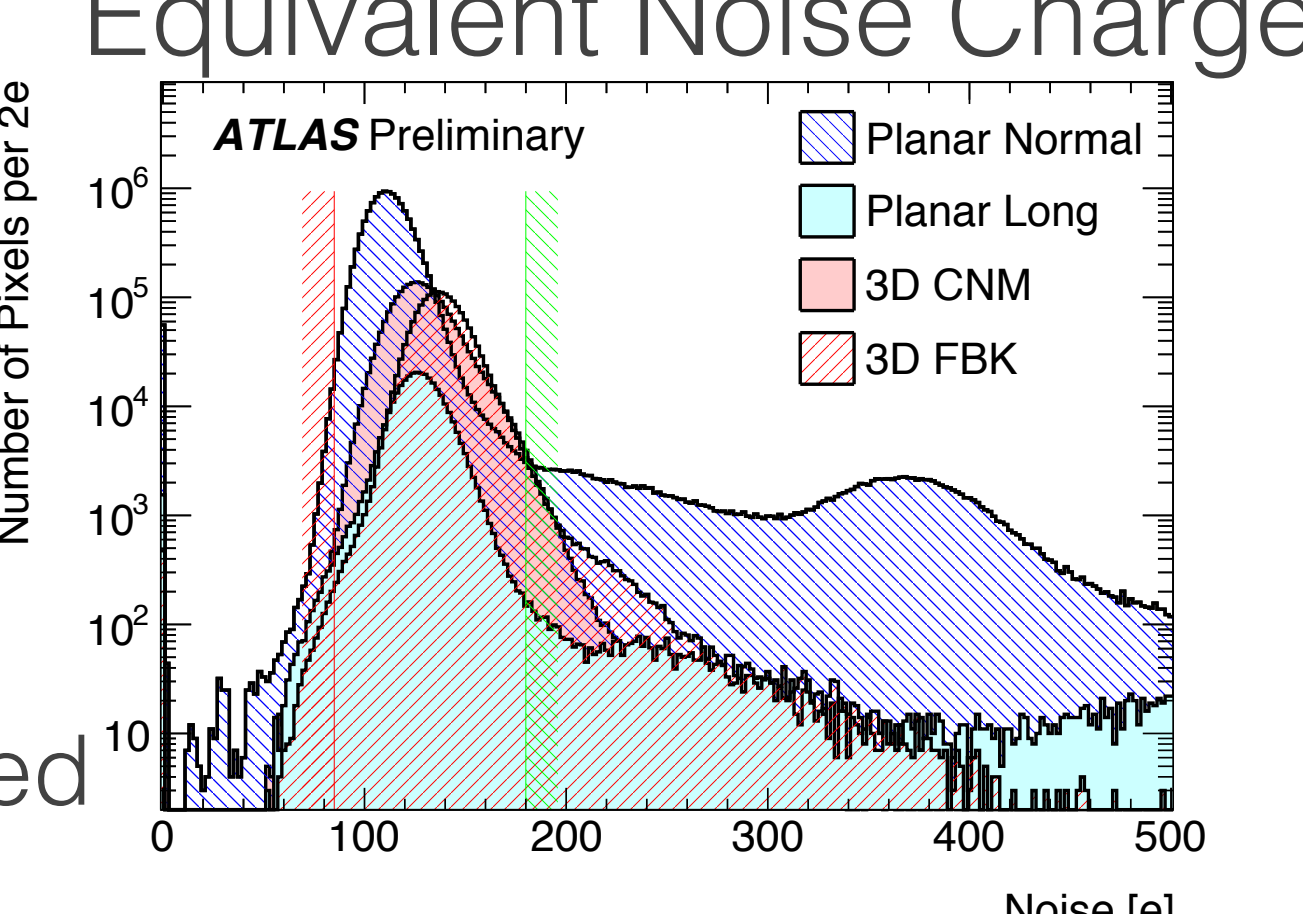

$99.8 \%$ pixels passed 10 ind 0 .

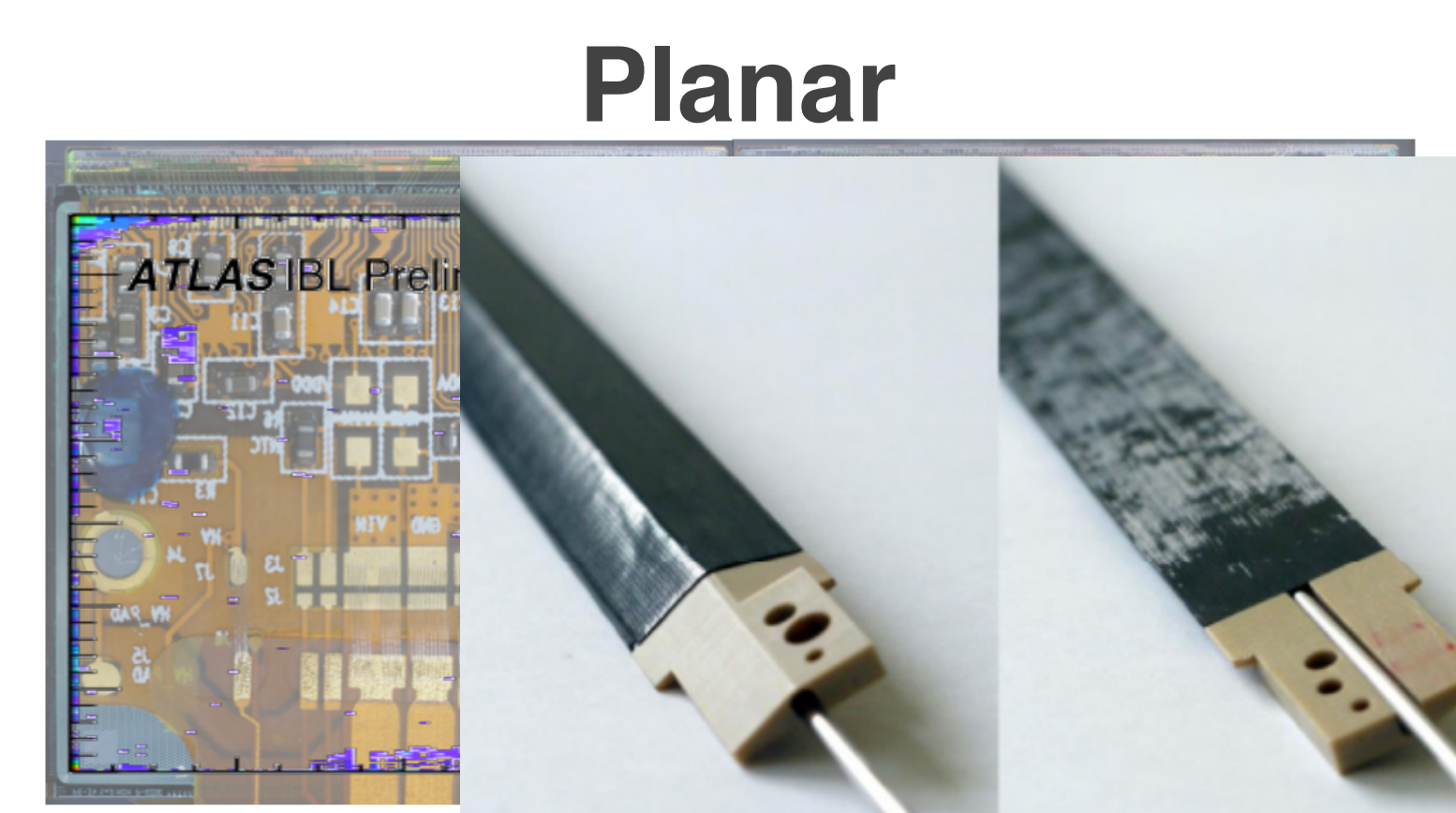

$3 \mathrm{D}$

Overlay of the total number of disconnected pixels for planar and 3D sensors loaded onto staves with pictures of doublechip and single-chip modules.

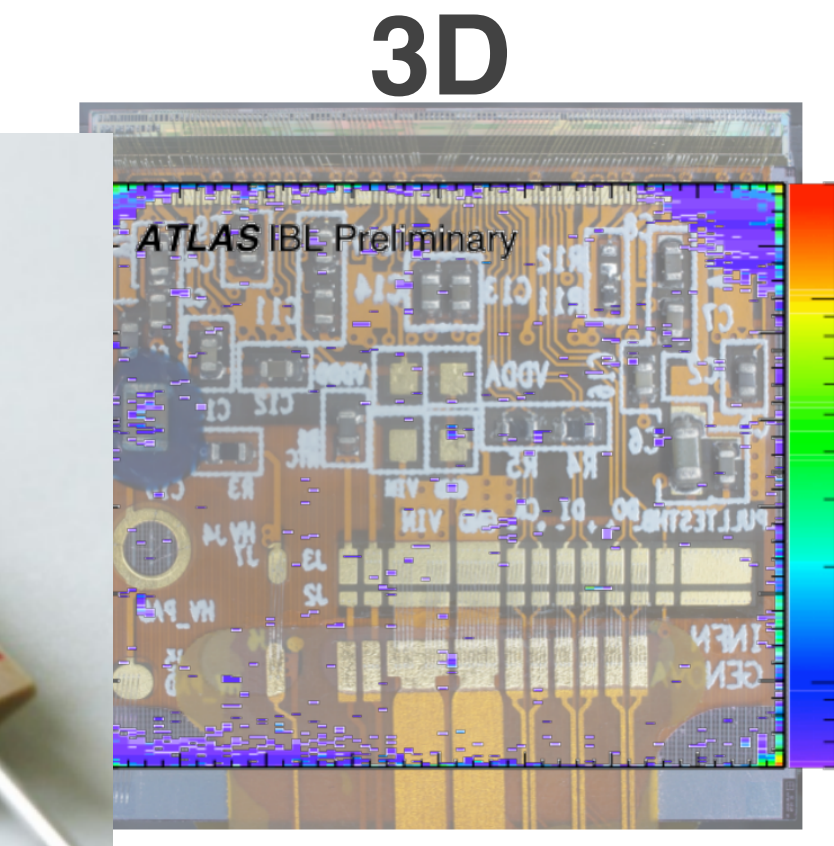

\section{Conclusion}

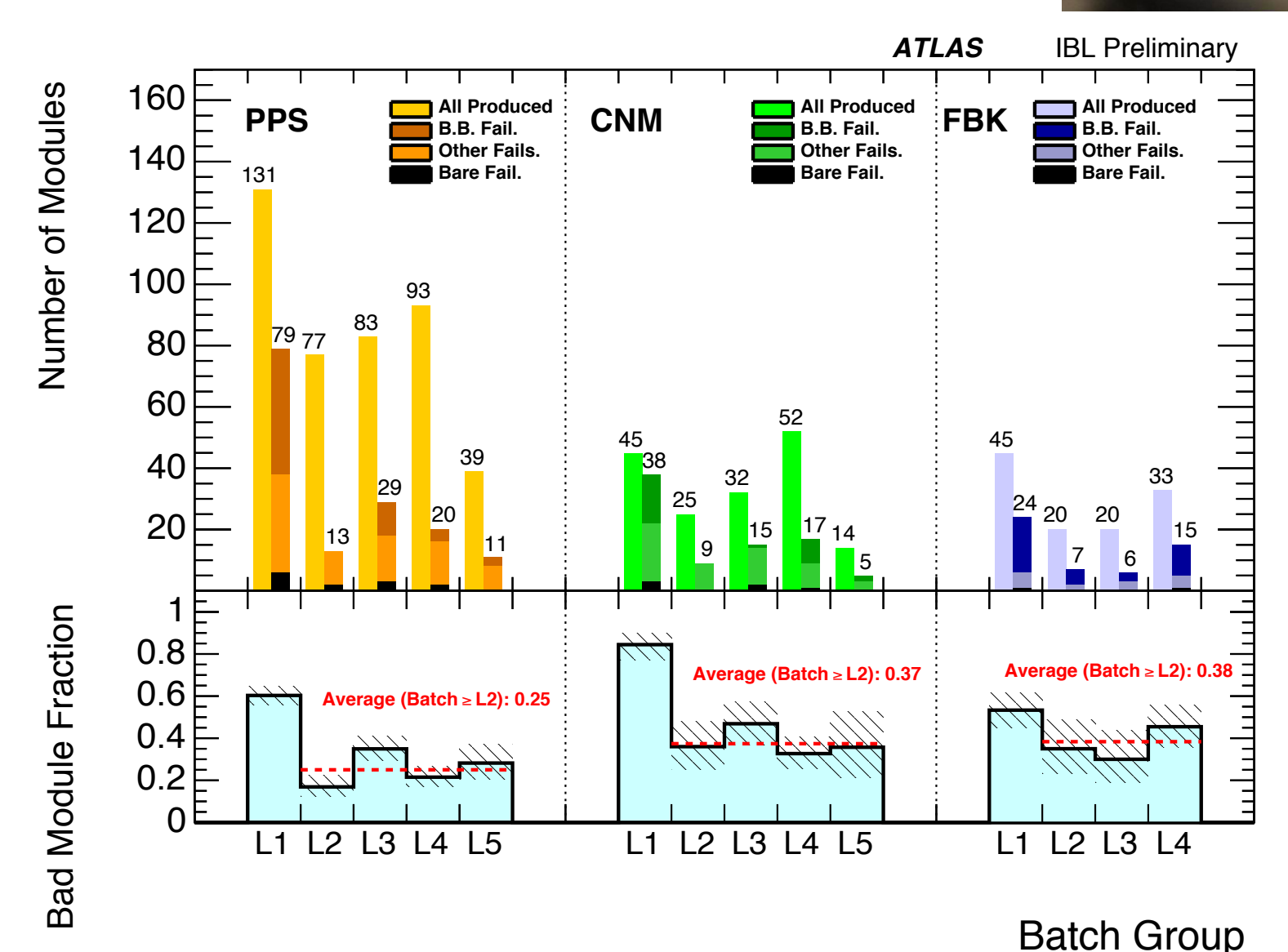

A good yield of the IBL module production was achieved $(\sim 75 \%$ for planar and $\sim 62 \%$ for 3D). Success in first large scale application of 3D sensor technology and implementation of new large size front-end chip is an important milestone for future upgrade of pixel detectors. The IBL has been inserted into the core of the ATLAS detector in May 2014. 